\title{
Influence of New Media on Traditional National Sports of Intangible Cultural Heritage Spreading in Universities
}

\author{
$\mathrm{Li} \mathrm{Li}$ \\ Shaanxi Xueqian Normal University \\ Xian, China
}

\author{
Rong Zhao \\ Shaanxi Xueqian Normal University \\ Xian, China
}

\begin{abstract}
With dramatic de velopment of information technology, the new media emerges at the right moment. The influence of it on traditional national sports culture of intangible cultural heritage spreading in universities of our country cannot be underestimated. In recent years, it has become another important problem of university education in our country about how to strengthen the effectiveness of traditional national sports culture of intangible cultural heritage spreading in the new media environment. Basing on practical working experience and looking up a large number of literatures, the author first set forth the characteristics of new media dissemination; secondly, analyzed the influence of new media on traditional national sports of intangible cultural heritage spreading in universities; finally, put forward effective strategy for traditional national sports of intangible cultural heritage spreading in universities under the new media environment, hoping to provide effective reference.
\end{abstract}

Keywords—new media; traditional national sports; spread in universities; influence; strategy

\section{INTRODUCTION}

In recent years, new media is booming and brings strong impact for the transmission of traditional media information. The so-called new media is defined to distinguish from the traditional newspapers, television and magazine. The rise of new media changes the position of audiences and enriches the way of production, transmission and receiving of information, which greatly meet different needs of the audiences. The advantages of new media such as strong interactivity and timeliness make it highly favored in universities. Under the background of new media and quality-oriented education, universities in our country actively change teaching concept, method, target and so on. New media has been widely applied in information transmission of traditional national sports culture of intangible cultural heritage in universities of our country. This article explores from three aspects, namely the propagation characteristics of new media, the influence of new media on traditional national sports of intangible cultural heritage spreading in universities, and effective strategy for traditional national sports of intangible cultural heritage spreading in universities under new media environment, in order to provide important reference to realize the goal that our country turns from sports country to sports power.

\section{PROPAGATION CHARACTERISTICS OF NEW MEDIA}

\section{A. The Interactivity is Strengthened}

In terms of the previous media transmission, it holds dominant position in transmission resources and channel and belongs to unidirectional transmission with almost zero interaction with the audiences. Therefore, the traditional media transmission has serious deficiencies in the aspect of interaction. Nowadays, with dramatic develop ment of social economy and science and technology, the new media emerges at the right moment. The rise of new media strengthens the speaking right of audiences and makes the audience change from passive to active. Meanwhile, the new media sets up good platform for audience and transmitter to timely communicate and couples back information ${ }^{[1]}$. Under the situation of new media, the transmitter is no longer limited to media practitioners, but defined as each member of society who possesses network resource. In recent years, the number of internet users in our country rises continuously. Mobile phone users and users of Sina micro-blog occupy a large proportion. New media produces a great impact for the transmission of traditional media. The dominant position of audience is established and respected.

\section{B. The Timeliness is Strengthened}

Compared with traditional media, the new media has incomparable advantages: fast transmission speed and strong timeliness. The existence of network makes the universal, full speed and full-time transmission of new media become reality. That is to say, the transmission of new media is not limited to time and space. Besides, when releasing news, the new media directly skips links such as type setting and printing, and can synchronously spread and report unexpected events, which help to improve the timeliness of transmission. At the same time, with fast development of computer networks and information technology, producers and transmitters can release and spread information whenever and wherever possible. The 
audience can also receive information whenever and wherever possible. This shows that the transceiver of information and transmission signal are of great important and necessary conditions for new media to carry out information dissemination activities.

\section{The Content and Form are Enriched}

Under the background of new media, the information becomes global and the amount is vast. The rise of new med ia makes each member of society who occupies network resources become message sender and changes the previous pattern that the information transmission is restricted by time and space. According to the investigation, new media can provide a large number of information, which mainly embodies in aspects of life, study and entertainment. It is beneficial for meeting the requirements of different audiences and information. The existence of new media enriches not only the content but also the way of information transmission. The survey finds that the ways of information transmission of new media mainly include text, video and audio, etc. Therefore, the audience can receive information through reading and listening. For the information transmission of new media, the paths for transmitter and audiences to deliver, spread and receive information tend to be diversified. For example: when producers and transmitters release and spread news, they can do it with the help of mobile devices such as mobile phone, computer and tablet PC, etc. Therefore, the new med ia accelerates the transmission of information, reducing the cost and increasing efficiency. At present, the new media develops continuously. Traditional media realizes the importance of technology reform and gradually eliminates the limitation between new media and it. The emergence of new media strengthens the speaking right of audience. The message sender is no longer limited to media practitioners.

III. INFLUENCE OF NEW MEDIA ON TRADITIONAL NATIONAL SPORTS OF INTANGIBLE CULTURAL HERITAGE SPREADING IN UNIVERSIT IES

New media produces strong impact for the way of traditional information transmission. The transmission of traditional national sports of intangible cultural heritage in universities is also strongly influenced. ${ }^{[2]}$

\section{A. The Direction of Traditional National Sports Culture of Intangible Cultural Heritage Spreading in Universities Changes}

It changes from unidirectional to bidirectional. New media is the inevitable product of high development of information technology. It provides broad platform for information transmission and fundamentally changes the content and way of sports culture transmission in universities. Under the new media environment, traditional media actively seeks the breakthrough of transmission concept and form in order to pursue better development for it. Therefore, traditional media devotes greater efforts to referring to new media and integrating new media. It is well-known that the sports channel of CCTV station is the most authoritative propagating source of sports culture in China. In new media age, it also positively constructs and expands channels of transmission of network new media. Besides, in the aspect of communication content, it absorbs the advantages of information transmission of new media to upgrading competitive capacity of its own and then attracts more audiences. In some sense, the change of CCTV sports channel drives the change of transmission of traditional national sports culture of intangible cultural heritage in universities. The rise of new media brings serious challenges for gym teachers in universities. It requires gym teachers in universities to carry out the transmission of traditional national sports culture, at the same time, make good use of new media such as website, WeChat and mobile phone and take full advantage of the strong interactivity and timeliness of new media, strengthen information exchange and discussion of traditional national sports culture between teachers and students, as well as between students and students, and then improve the efficiency of traditional national sports culture of intangible cultural heritage spreading in universities of our country.

In New Media Age, the Traditional National Sports Culture of Intangible Cultural Heritage Spreading in Universities Strengthens the Integration of Media.

There is no doubt that the emergence, development and application of media have inseparable relationship with the progress of science and technology. The development of network and electronic technique creates the new media and greatly improve people's living standards. Practice has proved that the emergence of new med ia has a positive effect on people to spread and receive information, and then enriches the content and way of the transmission of traditional national sports culture in universities and makes it become diversified. How to strengthen the use of new media has become an important problem for universities in China to solve promptly. According to many years of experience in teaching, the author thinks that universities should timely change the transmission concept and pattem. Universities must pay more attention to media convergence and then better adapt to the new media trend. At present, college students occupy great proportion in the users of new media. This shows that when universities use new media to carry out the transmission of traditional national sports culture, they will save a large number of manpower and material resources and help to improve the transmission efficiency of traditional national sports culture in universities. For media convergence, universities can set about from the following contents: Firstly, when planning and making the contents of traditional national sports culture, universities shall make good use of multiple media. For example: except for setting special website of sports culture, universities also should open official micro-blog and WeChat official accounts, create various channels for students to receive sports culture information rapidly and conveniently and actively participate in related research and discussion. Then, on the basis of information carrier, universities shall strengthen the use of multimedia technology, and then prompt the enrichment of content and form of information transmission of traditional national sports culture in universities. 


\section{B. Under the Situation of New Media, the Traditional National Sports Culture Spreading in Universities Mainly Relies on Media.}

In the previous information transmission, the traditional national sports culture spreading in universities has single path. The rise of new media improves the present situation and further enriches the route of transmission of traditional national sports culture in universities. The development of internet and information technology realizes transmitting whenever and wherever possible. Therefore, the new media dissemination changes students' learning style and makes them choose time and space for learning according to their actual academic performance. In new media time, the transmission of traditional national sports culture in universities will no longer only spread information. It expands to the scope of sports information service. [3] Meanwhile, students are no longer subject to the limitations of time and space. They can comment on and spread sports culture information at any time. With continuous development of science and technology, intellectual products such as computers, mobile phones and tablet devices appear and update constantly. Therefore, universities shall take full advantage of these scientific and technological resources to make teachers and students can spread and receive information about traditional national sports culture whenever and wherever possible.

\section{EFFECTIVE STRATEGY FOR TRADITIONAL NATIONAL} SPORT S OF INTANGIBLE CULTURAL HERITAGE SPREADING IN UNIVERSIT IES UNDER NEW MEDIA ENVIRONMENT

\section{A. Devote Greater Effort to Concerning About and Integrating New Media Platform.}

In new media time, the manifestation form, carrier and content of transmission of traditional national sports culture in universities become diversified. It no longer spreads only by relying on forms of text, pictures and image-text, but leads audio and video in transmission, strengthening interactivity and timeliness, and then provides teachers and students with visualized, vivid and comprehensive sports information. Meanwhile, the means and ways of transmission are also improved effectively. Routes of transmission such as BBS, blog and post bar emerge at the right moment. Therefore, in order to efficiently spread the target of traditional national sport culture, universities must take full advantage of these new media resources to realize comprehensive transmission of traditional national sports culture. ${ }^{[4]}$ Besides, teachers in universities shall reinforce learning timely and continuously, enrich new media and network knowledge, and then improve teaching level and ability. Through learning, they master the skills to use new media such as microblog, WeChat and blog and better spread information about traditional national sports culture. At the same time, on the basis of understanding and applying new media, teachers can fully excavate, use and develop new media resources to enrich the spreading form of information on traditional national sports culture. It's worth noting that universities provide rich teaching resources such as images, texts and videos through integration of new media to deepen students' learning and understanding for sports culture, and then promote the quality of information transmission of traditional national sports culture in universities under new media environment.

\section{B. Establish Multiple Paths for Transmission of Sports Culture.}

The emergence of new media makes the way of information transmission become more diversified to some extent. So many universities in our country also should follow the tendency of development of times, base on traditional spreading form of sports culture and integrate the spreading form of new media. In actual operation, it is necessary to match them, keep the authority of traditional media as far as possible, and give full play to the flexibility of new media and reasonably make use of new media on the basis of attaching great importance to the effect of new media. Through integrating the new and diversified propagation path of new media, universities can make the transmission of sports culture spread faster and wider, fully attract students' interest and make them actively understand sports culture, achieving ideal propagation effect.

\section{Improve Sports Culture Quality of College Students}

The success of the work on information transmission of traditional national sports culture in universities is embodied in the promotion of students' sports culture quality to some extent. In order to improve students' comprehensive qualities of sports culture, universities need to start from the following aspects: Firstly, they can invite authoritative experts of sports education in schools or sports stars who enjoy some reputation in the region to campus to give lectures and make students understand knowledge and content related to sports culture; [5] secondly, they can organize students to carry out relevant speeches and competitions about knowledge of sports culture and urge students to actively understand relevant contents of sports culture through competition; lastly, universities can attract students to participate in evaluation and discussion activities of media platform through various ways, make students give their opinions and understanding for sports culture, and then raise their awareness to put forward independent opinion and feelings for sports culture. Through the above ways, universities can effectively improve students' sports culture quality and realize the target of sports culture transmission.

\section{CONCLUSION}

All in all, new media has a great influence on information transmission of traditional national sports culture of intangible cultural heritage in universities and further lays solid foundation for the development of sports culture in universities. The effective transmission of information about sports culture can realize the goal that our country turns from sports country to sports power. College students are the main groups to apply new media. Universities should keep pace with the times, make full use of and integrate new media 
platform, improve the interactivity and timeliness of information transmission of traditional national sports culture, and then provide rich and diversified information on sports culture, strengthen the learning and understanding of students for sports culture, promote the process of development of sports cause and spirit, comprehensively improve the overall quality of college students and provide a large number of talents with high quality of sports for the society. We hope that universities in our country can pay attention to effective measures such as integrate new media platform, establish various paths for the transmission of sports culture, and improve sports culture quality of college students, and make more outstanding achievements in transmission of information on traditional national sports culture.

\section{REFERENCES}

[1] Yang Minglei, Feng Haitao, Li Yongping. Influence and Strategy of WeChat on Intangible Cultural Heritage Resources of Sports to Spread in Universities [J], News Front, 2015, 10: 139-140

[2] Dong Jinguo. Discussion on Significance of National Physical Culture Items to Implement in Public Physical Education Class in Universities under New Media Environment [J], Journal of Chifeng University (edition of nat ural science), 2015, 17: 179-180

[3] Liu Ge. Looking the Protection and Inheritance of Traditional National Sports in China from the Perspective of Int angible Cultural Heritage [J], Zhejiang Sports Science, 2012, 04: 5-10

[4] Zhu Hongjing. Discussion on Popularization and Promotion of Minority National Sports in Universities-Take Universities in Guizhou as an Example [J], Journal of Yulin Normal University, 2012, 05: 97-101

[5] Yuan Xu, Zhao Jianlin. Discussion on Transmission of Minorities' Traditional Sports Culture in Universities [J], Journalism Lover, 2010, 24: 94-95. 